\title{
Gassings due to methylene chloride, xylene, toluene, and styrene reported to Her Majesty's Factory Inspectorate 1961-80
}

\author{
M A BAKINSON' AND R D JONES ${ }^{2}$ \\ From the TUC Centenary Institute of Occupational Health, ' London School of Hygiene and Tropical \\ Medicine, London WCIE 7HT, and Health and Safety Executive, ${ }^{2}$ Bootle, Merseyside, UK
}

ABSTRACT For the period 1961-80, 118 cases of industrial gassings caused by the solvents methylene chloride, xylene, toluene, and styrene were reported to Her Majesty's Factory Inspectorate. The data have been collated and analysed according to the predetermined criteria of age, sex, mode and circumstances of use, clinical effect, and outcome. The means of collection of the data and their objectivity is discussed. The study shows the narcotic effect of these solvents and underlines the dangers of their use in confined spaces. Symptoms were most commonly attributable to the nervous and respiratory systems. The problem of addiction and the vulnerability of the younger worker is also discussed.

Cases of industrial gassings have been reported by means of a well defined procedure to the medical branch of the Health and Safety Executive and their predecessors, the Medical Inspectorate of Factories, for over 40 years. A previous review of these data looked at the cases reported for three common chlorinated hydrocarbon solvents in the period 1961-80.' This review suggested that younger workers experienced proportionately greater morbidity as a result of industrial gassing than their older workmates. To determine whether this effect could be shown for other common industrial solvents, a similar study was set up to review industrial gassings due to methylene chloride, xylene, toluene, and styrene reported in the same period (1961-80).

\section{Data source}

Under section 80 of the Factories Act, any accident was notifiable if it caused loss of life to a person employed in premises subject to that Act, or if it disabled any such person for more than three days from earning full wages at the work in which he was employed.' Cases were notifiable to Her Majesty's Inspector responsible for that area who, in the case of a gassing accident, then informed the employment medical adviser (before 1973 this would have been an appointed factory doctor or medical inspec-

Received 25 January 1984

Accepted 16 May 1984 tor of factories). This medical officer then reported on the medical aspects of the case, a copy of his report being sent to head office for retention. I I some cases it may have been subsequently found that circumstances of the incident did not meet the statutory requirements for notification under the Act. For the purposes of this study, however, we have used the medical reports on all cases of poisoning due to one of these solvents.

\section{Methods}

Records relating to gassing accidents due to any of the four solvents under consideration were scrutinised. For each incident the date of occurrence, age, and sex of the victims were noted. Details of mode of use and circumstances of use, together with clinical effect and outcome, were also extracted. A particular note was made in each case as to whether the incident had occurred in a confined space. An incident was deemed to have occurred in a confined space if this wording was used in the description of the circumstances or if the authors considered that the incident had occurred in circumstances which should be so defined. The term "confined space" is used in section 30 of the Factories Act $1961 .^{2}$ For the purpose of this paper, a confined space was defined as "any chamber, pit, vat, or tank without natural or designed ventilation."

Each clinical record was searched for evidence of 
toxic effect according to the specific predetermined classification shown below:

(1) Central nervous system: (a) Where mention was made that an affected person had been rendered unconscious, this was accepted as an effect of the incident. If specific mention of such an effect did not appear in the record then it was assumed that the victim had remained conscious. (b) Other central nervous system symptoms specifically recorded were headache, dizziness or giddiness, confusion, drunkenness, incoordination, and paraesthesia.

(2) Gastrointestinal symptoms.

(3) Hepatic involvement as evidenced by ( $a$ ) clinical signs or $(b)$ liver function tests.

(4) Renal toxicity as shown by $(a)$ clinical symptoms and signs, $(b)$ urine analysis, or $(c)$ other biochemical investigations.

(5) Symptoms or signs attributable to the respiratory system.

(6) Evidence of any haematological abnormality.

(7) Effect on the heart, including chest pain, evidence of arrhythmias, and inappropriate sudden collapse - that is, where there was witness to lack of central nervous system signs or symptoms immediately before collapse.

Each record was especially scrutinised for any mention of possible addiction.

\section{Results}

A total of 118 victims of gassing accidents due to one of the four solvents were reported for the period 1961-80. In the same period 11 cases were reported due to mixtures of xylene or toluene with other benzene homologues. Figure 1 shows the distribution of the reported cases during the period for each specific solvent and for all solvents. There is no obvious linear trend in the number of cases through the years but peak incidences occurred in 1972 and 1975 . Table 1 shows the actual number of cases attributable to each solvent.

AGE

Precise age was available for all but two of the cases, in which the victims were merely stated to be "over 21." Of the 129 cases, 20 were under 21 . In this group central nervous system depression resulted in unconsciousness in $13(65 \%)$ whereas for the group aged over 21,40 of the 109 victims were noted to have lost consciousness $(36.7 \%)$. This difference, tested by means of a $2 \times 2$ contingency table, reaches significance at the $5 \%$ level $(p=0.018)$. The age distribution of severity of central nervous system symptoms is shown in fig 2 , from which it may be noted that only in the 15-19 age group are

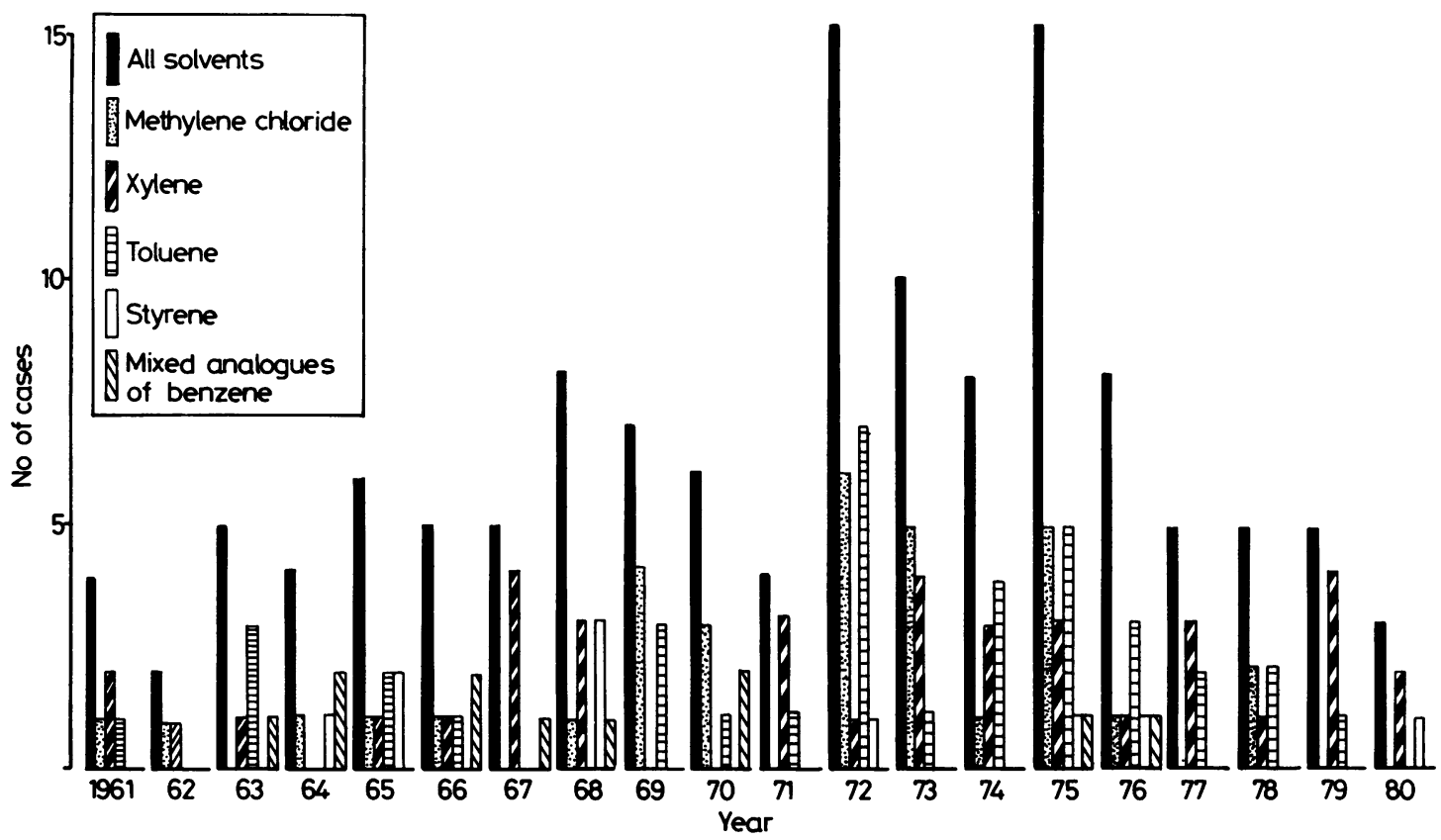

Fig 1 Cases per year for specific solvents 1961-80. 
Table 1 Cases attributable to each solvent

\begin{tabular}{lc}
\hline Solvents & No affected \\
\hline Methylene chloride & 33 \\
Xylene & 38 \\
Toluene & 37 \\
Styrene & 10 \\
Mixture of toluene or xylene with another & 11 \\
$\quad$ benzene homologue & 129 \\
\hline
\end{tabular}

there more victims rendered unconscious than those who were not.

SEX

Of the 129 cases reported, only 15 were women, two of these being rendered unconscious. Of the 114 men, 46 were rendered unconscious.

\section{MODE OF USE}

The uses to which the particular solvents had been put are shown in table 2 .

\section{CIRCUMSTANCE OF USE}

The circumstances of use were divided into whether work took place in a confined space or not. The results are shown in table 3 , from which it may be seen that unconsciousness occurred more often in those victims who were affected in confined spaces. Of the 53 people rendered unconscious, 40 were working in confined spaces, whereas only 30 of the 76 of those less affected had been working in a confined space. If one applies a goodness of fit chi squared to this then $\mathrm{p}=0.00006$.

\section{CLINICAL MANIFESTATIONS}

In the 118 gassings reported attributable to specific solvents clinical manifestations were most often related to the central nervous system with 48 people becoming unconscious, including four who died. Of the 70 individuals in whom unconsciousness did not occur, 53 reported central nervous system symptoms, of which dizziness was the most frequent (see table 4). Headache and dizziness were most commonly reported in cases of toluene gassing.

Gastrointestinal symptoms were next in frequency to central nervous system symptoms with 37 victims experiencing such effects, of which nausea or vomiting were most frequent. No gastrointestinal symptoms due to styrene were reported.

No evidence of blood dyscrasias was reported in

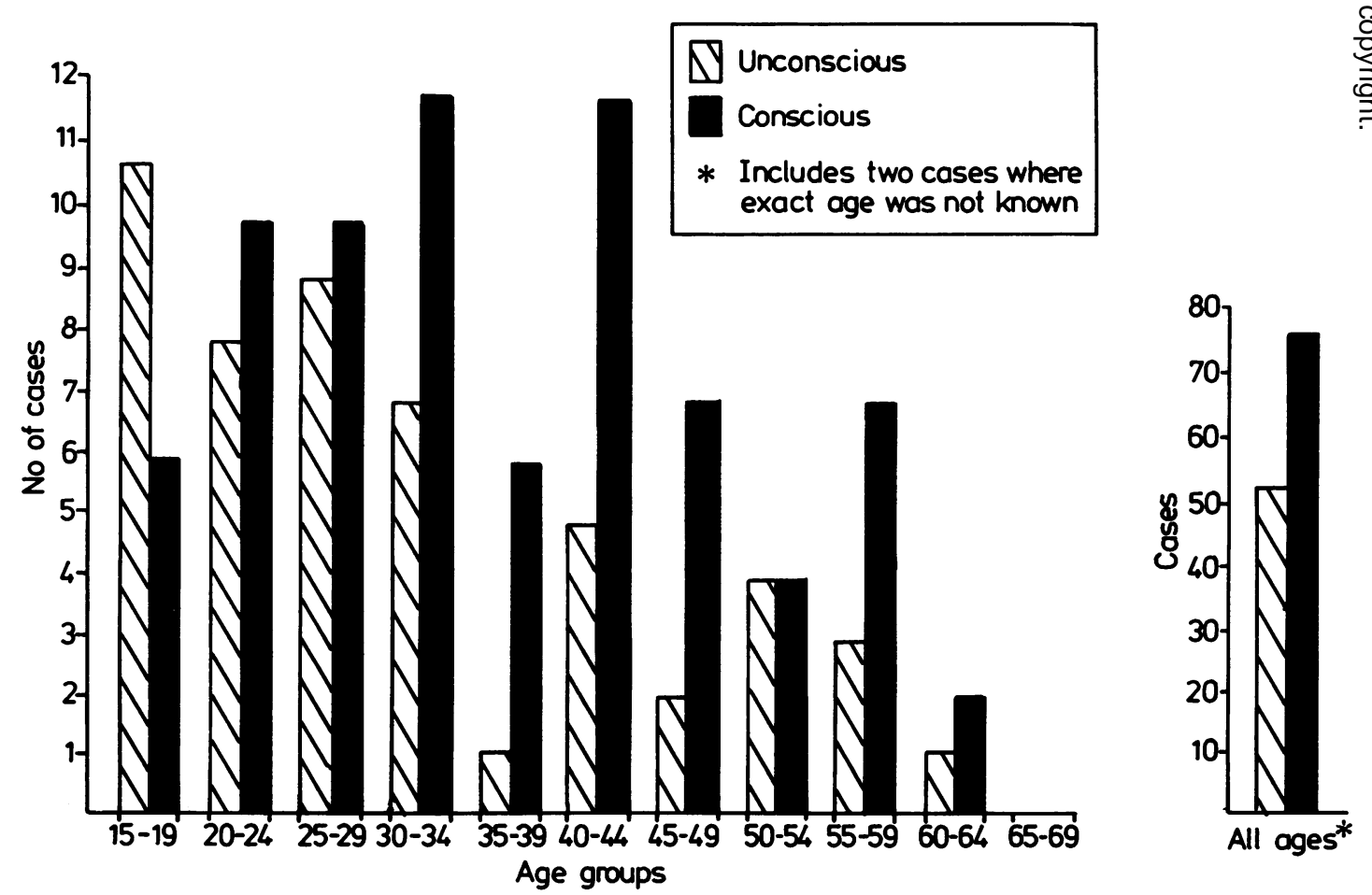

Fig 2 Number of conscious and unconscious (including fatal) cases from all four solvents in five year age groups 1961-80. 
Table 2 Mode of use of solvents at time of accident

\begin{tabular}{|c|c|c|c|c|c|}
\hline & Methylene chloride & Xylene & Toluene & Styrene & Mixed homologues \\
\hline \multirow{7}{*}{$\begin{array}{l}\text { Paint application } \\
\text { Manufacture of chemicals, paints } \\
\text { and glues. } \\
\text { Degreasing } \\
\text { Cleaning } \\
\text { Paint stripping } \\
\text { Glass reinforced plastic fabrication } \\
\text { Others }\end{array}$} & 3 & 28 & 8 & - & 5 \\
\hline & 9 & 5 & 11 & 1 & 4 \\
\hline & 3 & - & - & 1 & - \\
\hline & 9 & 5 & 9 & 2 & 1 \\
\hline & 8 & - & - & - & - \\
\hline & - & - & - & 6 & - \\
\hline & 1 & - & 9 & - & 1 \\
\hline
\end{tabular}

Table 3 Circumstance of use

\begin{tabular}{|c|c|c|c|c|c|}
\hline & \multicolumn{2}{|l|}{ Conscious } & \multicolumn{2}{|c|}{ Unconscious } & \multirow[b]{2}{*}{ Total confuned } \\
\hline & Confined & Not confuned & Confuned & Not confined & \\
\hline $\begin{array}{l}\text { Methylene chloride } \\
\text { Xylene } \\
\text { Toluene } \\
\text { Styrene }\end{array}$ & $\begin{array}{r}6 \\
8 \\
11 \\
3\end{array}$ & $\begin{array}{r}14 \\
13 \\
13 \\
2\end{array}$ & $\begin{array}{r}8 \\
16 \\
8 \\
5\end{array}$ & $\begin{array}{l}5 \\
1 \\
5 \\
0\end{array}$ & $\begin{array}{l}33 \\
38 \\
37 \\
10\end{array}$ \\
\hline $\begin{array}{l}\text { Toluene or xylene with another } \\
\text { benzene homologue } \\
\text { All solvents }\end{array}$ & $\begin{array}{r}2 \\
30\end{array}$ & $\begin{array}{r}4 \\
46\end{array}$ & $\begin{array}{r}3 \\
40\end{array}$ & $\begin{array}{r}2 \\
13\end{array}$ & $\begin{array}{r}11 \\
129\end{array}$ \\
\hline
\end{tabular}

Table 4 Clinical manifestation

\begin{tabular}{|c|c|c|c|c|c|c|}
\hline Symptom & All solvents & $\begin{array}{l}\text { Methylene } \\
\text { chloride }\end{array}$ & Xylene & Toluene & Styrene & $\begin{array}{l}\text { Toluene or xylen } \\
\text { with another } \\
\text { benzene } \\
\text { homologue }\end{array}$ \\
\hline $\begin{array}{l}\text { Total No of cases } \\
\text { CNS }\end{array}$ & 129 & 33 & 38 & 37 & 10 & 11 \\
\hline $\begin{array}{l}\text { Unconscious* } \\
\text { Conscious } \\
\text { General CNS }\end{array}$ & $\begin{array}{l}53 \\
76\end{array}$ & $\begin{array}{l}13 \\
20\end{array}$ & $\begin{array}{l}17 \\
21\end{array}$ & $\begin{array}{l}13 \\
24\end{array}$ & $\begin{array}{l}5 \\
5\end{array}$ & $\begin{array}{l}5 \\
6\end{array}$ \\
\hline $\begin{array}{l}\text { General CNS } \\
\text { Other CNS effects: }\end{array}$ & 53 & 19 & 14 & 18 & 13 & - \\
\hline $\begin{array}{l}\text { Headache } \\
\text { Dizziness }\end{array}$ & 31 & 9 & 5 & 14 & - & 3 \\
\hline $\begin{array}{l}\text { Dizziness } \\
\text { Confusion }\end{array}$ & 36 & 11 & 6 & 16 & 3 & - \\
\hline $\begin{array}{l}\text { Conrusion } \\
\text { Drunkenness }\end{array}$ & $\begin{array}{r}12 \\
7\end{array}$ & $\begin{array}{l}2 \\
1\end{array}$ & $\begin{array}{l}5 \\
3\end{array}$ & $\begin{array}{l}4 \\
3\end{array}$ & 1 & E \\
\hline $\begin{array}{l}\text { Incoordination } \\
\text { Paraesthesia }\end{array}$ & 5 & 1 & 2 & 1 & - & -1 \\
\hline $\begin{array}{l}\text { Paraesthesia } \\
\text { Gastrointestinal symptoms }\end{array}$ & 1 & 1 & - & - & - & - \\
\hline $\begin{array}{l}\text { Gastrointestinal symptoms } \\
\text { Liver }\end{array}$ & 42 & 13 & 12 & 12 & - & 5 \\
\hline $\begin{array}{l}\text { Liver } \\
\text { Renal }\end{array}$ & 4 & 1 & 3 & - & - & - \\
\hline $\begin{array}{l}\text { Renal } \\
\text { Respiratory }\end{array}$ & 32 & $\overline{4}$ & $\begin{array}{r}2 \\
13\end{array}$ & $\begin{array}{r}1 \\
10\end{array}$ & $\overline{3}$ & $\overline{2}$ \\
\hline Blood dyscrasia & - & - & - & - & - & - \\
\hline Cardiac & 1 & - & - & 1 & - & - \\
\hline
\end{tabular}

*Includes fatal cases. These are excluded from other sections in the table.

CNS = Central nervous system.

any of the 118 cases due to specific solvents or the 11 due to mixed exposure.

Thirty victims complained of respiratory symptoms, which included cough, breathlessness, and chest tightness, but respiratory symptoms were noted in only four of the 33 cases due to methylene chloride gassing.

Hepatic tenderness was reported in one case of methylene chloride poisoning, and also in a victim of xylene poisoning. In both cases liver function tests were normal. SGOT levels were raised in two other xylene gassing cases which together with a fatal case from the same incident have been reported by Morley et al. ${ }^{3}$

Increased frequency of micturition was reported in one case of xylene poisoning and in another case of toluene gassing. Raised blood urea was a feature of one of the cases of xylene poisoning described by Morley ${ }^{3}$ referred to above.

Cardiac symptoms were attributed to toluene by the investigating physician in the case of a 26 year old worker who felt dizzy and fainted after a sudden escape of toluene vapour that took two to three minutes to control. On admission to hospital the 
man was found to have a tachycardia with normal ECG.

Mention of possible addiction was looked for but found in only one case, that of a 17 year old worker rendered unconscious by xylene who had previously been observed by his workmates to sniff the solvent.

\section{DEATHS}

Four men (aged 17-54) died, one with each of the individual solvents studied. Three died in confined spaces whereas the fourth death, occurring in an open workshop, resulted from a substantial release of solvent fume. All deaths were attributed to acute narcosis resulting in respiratory depression.

Evidence of liver and spleen congestion was seen at necropsy in the man who had died from acute methylene chloride poisoning. Congestion of the liver and the renal cortex was reported at the necropsy of the fatal case of xylene poisoning which has been described elsewhere. ${ }^{3}$ There was also evidence of cerebral oedema.

The styrene death was attributed to asphyxia consequent on inhalation of vomit in an unconscious victim of narcosis. There were signs of swelling and congestion of the brain.

Detailed necropsy findings on the toluene gassing were not available but again death was reported to be due to narcosis.

\section{Discussion}

The data analysed cover the 20 year period 1961 to 1980 and are extracted from reports of various appointed factory doctors, employment medical advisers, and factory inspectors. Estimates of the number of employees at risk, or the amount of solvents used a year, were not available and so incidence rates and yearly comparisons cannot be made. Since the data essentially relate to the acute poisoning they provide no information on long term toxicity.

Whereas age, sex, and process are recorded consistently, the clinical assessments are subject to the clinical impression formed by a specific medical officer, whose investigations were often incomplete and in some cases carried out many weeks after the incident. Thus the details on any individual case will be determined by the time of presentation and the diagnostic policy pursued by the physcian in charge. The absence of positive evidence of an effect may indicate that such an effect was not investigated and cannot be taken as evidence for absence of that effect. The unstructured nature of the data inevitably means that any analysis performed must be limited and somewhat crude. To obtain some objectivity, a priori criteria were drawn up for extraction

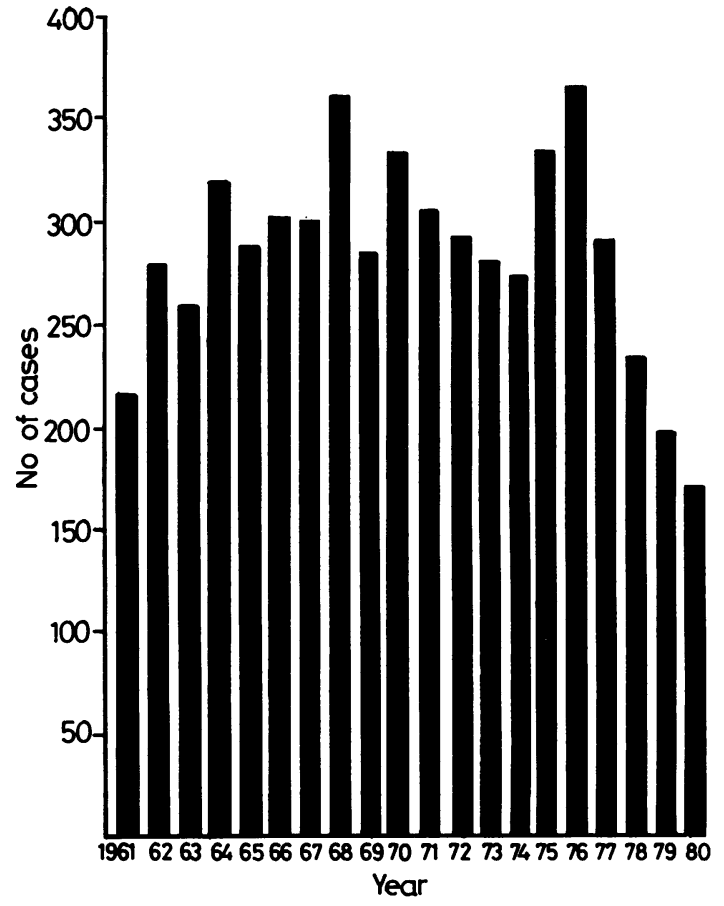

Fig 3 Cases per year of all gassing accidents 1961-80.

of data, but the possibility of subjective bias in extraction must still exist. The data presented here are important, however, because they enable us to appreciate the practical short term toxicity of these compounds as actually experienced in an occupational context and thus we are able to gain an impression of the range and relative frequency of problems posed by these agents. The presentation of our non-standardised data is justified therefore by their relevance, but the use of statistical significance tests on such material is questionable. Statistical considerations are therefore included with much reservation.

As during the period studied the reporting of accidents occurring in factories which caused more than three days incapacity from work was required by law one might expect most cases occurring to be notified. The value of any notification system will be lessened by the degree of under reporting that exists, but this series will include many if not most of all serious industrial gassing accidents occurring in the United Kingdom as a result of exposure to these solvents. From the data presented it is difficult to discern any trend in gassing accidents with time over the period 1961-80. There is perhaps a tendency for a particularly high incidence between 1972 and 
1976. This may be due to reporting practices but is not reflected in the notifications for all gassing accidents shown in fig 3 . There is a suggestion of declining notifications for all gassing accidents in the last two or three years of that period, which may be due to several factors including reporting procedures, better work practices, and declining industrial activity.

The study shows that more men than women become victims of gassing accidents and that male workers were often severely affected whereas female workers were more often mildly affected. The explanation for this pattern is probably due to the different distribution of occupation between the sexes within industry.

As in a previous review, a higher proportion of more severe solvent poisonings was found among the cases reported in younger workers. An explanation of this phenomenon might be that a bias exists for only the more severe cases in this age group to be notified. Surveys of the labour force in the United Kingdom ${ }^{4}$ indicate, however, that $10 \%$ of the potential workforce is aged 16 to 19 . As $13 \%$ of our cases were in this age group, the younger element do not seem to be underrepresented so that such a bias seems unlikely. Explanations for an increased susceptibility in young people may include inexperience, a less careful attitude, different work patterns, inadequate supervision, a physiological susceptibility, and solvent abuse. This excess in the younger age groups could be explained if a greater proportion of young people were being asked to work in confined spaces. A brief examination of the cases occurring in those under 21 , however, showed that whereas $50 \%$ of them were working in confined spaces this was not disproportionally different from the percentage found among older workers $(40 \%)$. Such a difference would not numerically have accounted for the excess of more severe accidents seen in the young.

In the present paper addiction was recorded only if this possibility was raised and specifically mentioned in the original report of the incident. When reviewing these incidents with hindsight, there are several that might have been brought about by solvent sniffing, but this is not confined to or especially prominent in the younger group. Probably, however, for all 129 cases solvent abuse is underreported.

For each solvent the predominant toxic effect appeared to be narcosis. For styrene the actual numbers were rather small and therefore little weight can be attached to the finding that $50 \%$ of those affected were rendered unconscious. For the remaining three solvents, the proportion sufficiently severely affected to become unconscious varied only slightly within the range $35-44 \%$.

Among the cases of methylene chloride gassing, no substantial evidence for hepatorenal or cardiac effect was found. This would support the view that exposure in man confirms the low toxicity observed in animals. ${ }^{5}$ The principal effects of excessive exposure were headaches, dizziness, and nausea, which is in keeping with the generally accepted toxic effects of methylene chloride. ${ }^{56}$ Respiratory symptoms did not seem to be a common result of exposure to methylene chloride.

While opinions as to the relative toxicity of toluene and xylene may differ, ${ }^{7}$ these alkyl benzenes are generally considered to exert similar toxic effects. In this series gassings due to both these solvents most commonly caused narcotic effects, respiratory irritation, and gastrointestinal symptoms. It is interesting to note from the cases reviewed here that exposure to toluene seemed more likely to produce symptoms of headache and dizziness than exposure to xylene. It is difficult to draw conclusions concerning the apparent hepatorenal toxicity of xylene by comparison with the other solvents reviewed as most of the data relating to hepatorenal toxicity of xylene in this study were obtained from the three cases reported by Morley et al, all of which occurred in the same incident after considerable and prolonged exposure.

The small number of gassings due to styrene precludes any inference being drawn.

Of the fatalities reported, one occurred in circumstances that might lead to a suspicion of solvent abuse, but it is not easy in such cases to be certain of the exact order of events leading to death. Similarly, it can be extremely difficult, if not impossible, to decide at necropsy whether the terminal event in a fatal gassing accident was due to depression of respiration or excitation of the myocardium resulting in a fatal arrhythmia. This latter possibility should be borne in mind, even though all the fatalities in this study were attributed to respiratory depression.

The data presented demonstrate well the special hazard associated with the use of solvents in a confined space, and the series underlines that the main practical health hazard of these compounds is their ability to produce narcosis.

\section{References}

' McCarthy TB, Jones RD. Industrial gassing poisonings due to trichlorethylene, perchlorethylene, and 1-1-1 trichloroethane, 1961-80. Br J Ind Med 1983;40:450-5.

${ }^{2}$ Factories Act, London: HMSO, 1961.

${ }^{3}$ Morley R, Eccleston DW, Douglas CP, Greville WEJ, Scott DJ, Anderson $J$. Xylene poisoning: a report on one fatal case and 
two cases of recovery after prolonged unconsciousness. $\mathrm{Br}$ Med J 1970;iii:442-3.

${ }^{4}$ Labour Force Survey. London: HMSO, 1980.

${ }^{5}$ Torkelson TR, Rowe VK. Patty's textbook of industrial hygiene and toxicology. 3rd ed. Vol 26. New York: John Wiley \& Son,
1981:3449-55.

- Sittig M. Hazardous and toxic effects of industrial chemicals. Noyes Data Corp, 1979:304.

' Documentation of threshold limit values. 4th ed. Cincinnati: American Conference of Government Industrial Hygienists, 1980.

\section{c \\ $\overline{\overline{3}}$ (D}

